\title{
ICT Infrastructure Management of Rural and Community Banks in Ghana the Role of ARB Apex Bank
}

\author{
Article by Samuel Chris Quist \\ Regent University College of Science and Technology, Ghana \\ E-mail:chrisquist@yahoo.co.uk
}

\begin{abstract}
Technology has become the bedrock on which all organizations thrive. Rural and Community Banks are no exception from this rule, as such to leverage on the current technological advancement, Rural and Community Banks (RCB) must invest heavily in highly sophisticated Information and Communication Technology (ICT) systems. As part of the Core functions of the ARB Apex Bank which serves as a mini central bank, is to provide ICT services and Training of IT staff that manage Rural and Community Banks. This paper highlights on the core mandate of the supervisory bank of the Rural and Community banks, ARB Apex bank on the Management of the ICT infrastructure of RCBs in Ghana, the modalities, the challenges as well as the successes in taking secured and reliable banking services to rural communities in Ghana. ARB Apex Bank has progressively introduced high level technology into Rural and Community banking making them very competitive even on the international space.
\end{abstract}

Keywords: Rural and Community Bank, ICT infrastructure, ARB Apex Bank, Electronic Banking, Technology Management.

\section{Introduction}

Information and Communication Technology (ICT) is currently the highway on which the success of each organization depends and cruise on. The level of infrastructure investment determines how seamless or rugged this highway may be and as such determine the success of the organization. ICT Infrastructure development determines the rate of growth of an organization however as stated by Lucas (2008), the ability to manage the ICT infrastructure effectively is key to the success of the organization or industry. The main aim of ICT infrastructure investment in most organization is to increase accessibility, availability, flexibility without compromising on security of the organization's data which is an essential and integral part of the survival of the organization. The ICT infrastructure of each organization encompasses all the methods of collecting data, storing and accessing data, processing data and disseminating the information generated from the data. Data loss of any form is detrimental to an organization, but data loss due to intentional breaches from hackers or unauthorized users or breaches in ICT infrastructure management policies is disastrous and distractive to an organization.

Ghana currently has about fifty percent (50\%) of her population living in the rural areas around the ten regions. Though Ghana's urban population is on the ascendancy with a 3.4\% annual rate of urbanization according to 2015 estimates from the 2010 national census, Ghana continued to be a nation of rural communities with a lot of people living in urban areas having close associations to their rural communities. In an attempt to perpetuate this pattern of rural urban residency and thereby to lessen the consequent socioeconomic impact on urban development, the "Rural Manifesto", which assessed the causes of rural underdevelopment, was introduced in April 1984. Development strategies were evaluated, and some were implemented to make rural residency more attractive. As a result, the Bank of Ghana established more than 120 rural and community banks to support rural entrepreneurs, and the rural electrification program was intensified in the late 1980s. 
DOI: $10.21522 / \mathrm{TIJAR} .2014 .04 .02 . A r t 002$

ISSN: $2520-3088$

Ghana established her first Rural and Community Bank in 1976 primarily to provide banking services to the rural population, providing credit to small-scale farmers and businesses and supporting development projects (Tsamenyi \& Shazad, 2008). Ghana currently has over one hundred and thirty-five rural and community banks spread over the ten regions. Most of the Rural and Community Banks (RCBs) are locally owned and managed with ARB Apex Bank serving as the supervising clearing bank under the regulation of the Bank of Ghana, which owns shares in the rural banks (Ansah, 1999).

This research paper seeks to highlights on the core mandate of the supervisory bank of the Rural and Community banks, ARB Apex bank on the Management of the ICT infrastructure of RCBs in Ghana, the modalities, the challenges as well as the successes in taking secured and reliable banking services to rural communities in Ghana.

\section{General functions of ARB apex bank}

As the supervising clearing bank of the rural and community banks in Ghana ARB Apex Bank which was established in January, 2000 has as its vision to "leverage on leading edge technology to increase the satisfaction of Rural and community Banks and their customers and expand access to financial services in the rural economy". To be able to effectively achieve this vision they have a mission "To provide sustainable banking and non-banking support services to the Rural and Community Banks with the aim of improving their operational efficiency and customer service, thereby transforming them into efficient financial institutions, which can effectively address the banking needs of the communities in which they operate" with their core values curled in the acronym SERVICE; that is Speed in delivery, Efficiency, Respect, Versatility, Integrity, Commitment and Effectiveness.

A critical look at the vision, mission and core values of ARB Apex Bank indicates or suggest an unavoidable mention of ICT infrastructure investment and management to be able to successful as a corporate entity. As a supervising bank, their core functions are;

- $\quad$ Keep accounts and maintain primary cash reserves.

- Monitor, inspect, supervise and ensure compliance.

- $\quad$ Lend funds.

- Handle cheque clearing activities.

- $\quad$ Provide specie services.

- Supply cash and receive excess cash.

- $\quad$ Render funds management services.

- Guarantee payment instruments.

- $\quad$ Provide audit and inspection services.

- Develop credit assessment procedures and monitor loans and advances.

- $\quad$ Provide ICT services.

- Provide training for staff and directors.

- $\quad$ Provide a deposit insurance scheme to protect deposits of customers.

\section{Technology dependent product}

ARB Apex bank over the years have introduce several technology dependent products to move CBs almost parallel to urban international banks. These technology dependent products have made the RCBs very competitive. Some of such products include Remittance Services and E-Banking.

\section{Remittance services}

ARB Apex bank operates both international and local funds transfer services through the RCBs, the remittance services offered are;

a. Apex Link: an instant domestic money transfer product developed to address the money transfer needs of people within the rural communities and peri-urban centres. It provides an opportunity to transfer money to all parts of the country through the network of rural and community banks dotted all over Ghana with over 800 outlets. 
b. Foreign Remittance: ARB Apex bank also offers international remittance services such as Western Union and MoneyGram.

\section{Method}

The research paper was conducted as an exploratory research to understand the role of ARB Apex Bank in managing the ICT infrastructure of Rural and Community Banks in Ghana. It was intended to highlight the strengths that the Rural and Community banks accrue from the management of the ICT infrastructure by a supervisory Bank as well identify the potential challenges and the gray areas. Open ended questionnaire was administered to the Deputy ICT director of the supervisory bank. The workflow and chain of command from the IT director to the grass root managers of the ICT infrastructure at the rural and community banks was also studied critically.

\section{Results and discussion}

ARB Apex bank operates a private cloud system that runs all the applications as well as the infrastructure of the Rural and Community banks. Prior 2009, all the Rural and Community Banks operated their single servers with different software and hardware architecture. The bank had to do all the networks to their various branches. IT staffs from ARB Apex Bank only visited the banks to aid in. This was quite expensive, difficult to manage and supervise. This brought a lot of long down times since personnel had to be sent from the supervisory bank to solve sometimes very minor problems. This meant customers would be cut off from accessing their funds for the period of the down time.

\section{Rural financial services project (RFSP)}

The Ghana Rural Financial Support Project (RFSP) was a project co-financed by International Fund for Agricultural Development (IFAD), the World Bank and the African Development Bank (AfDB) as was aimed at promoting growth, reducing poverty and deepening rural financial intermediation. The project's objectives were building the capacity of the informal sector; building the capacity of Rural and Community Banks (RCBs); and building a supervisory institution (Apex Bank) to for institutional Support.

The RFS Project started in 2002 and was completed in 2008. RFSP was a sub-sector specific and country wide project with interventions at macro, meso and micro level. The overall objective was to complement government efforts in reducing poverty by broadening access to rural finance. The total cost of the Rural Financial Support Project was USD 22.9 million. According to the Project Performance Assessment report, the RFSP was consistent to national policies, IFAD's country strategy and rural finance policy, as well as to the national micro and rural finance development need. The report further stated that the project design had two (2) shortcomings; firstly, even though the design aimed at introducing linkages between informal and formal financial institutions as observed in India, it did not adapt the linkage model to the Ghanaian context. Secondly, the RFSP design did not articulate well the linkages with the other existing interventions in Ghana that could benefit from enhanced access to Rural Finance Services.

The report noted that the Ghana RFSP made lots of strives in its support to the rural and community bank network. Through the project the ARB Apex Bank was established as an umbrella organization of rural and community banks. According to the Project Completion Digests - 2010, the RFSP contributed significantly to the expansion of rural financial services and a more robust finance sector. 
DOI: $10.21522 /$ TIJAR.2014.04.02.Art002

ISSN: $2520-3088$

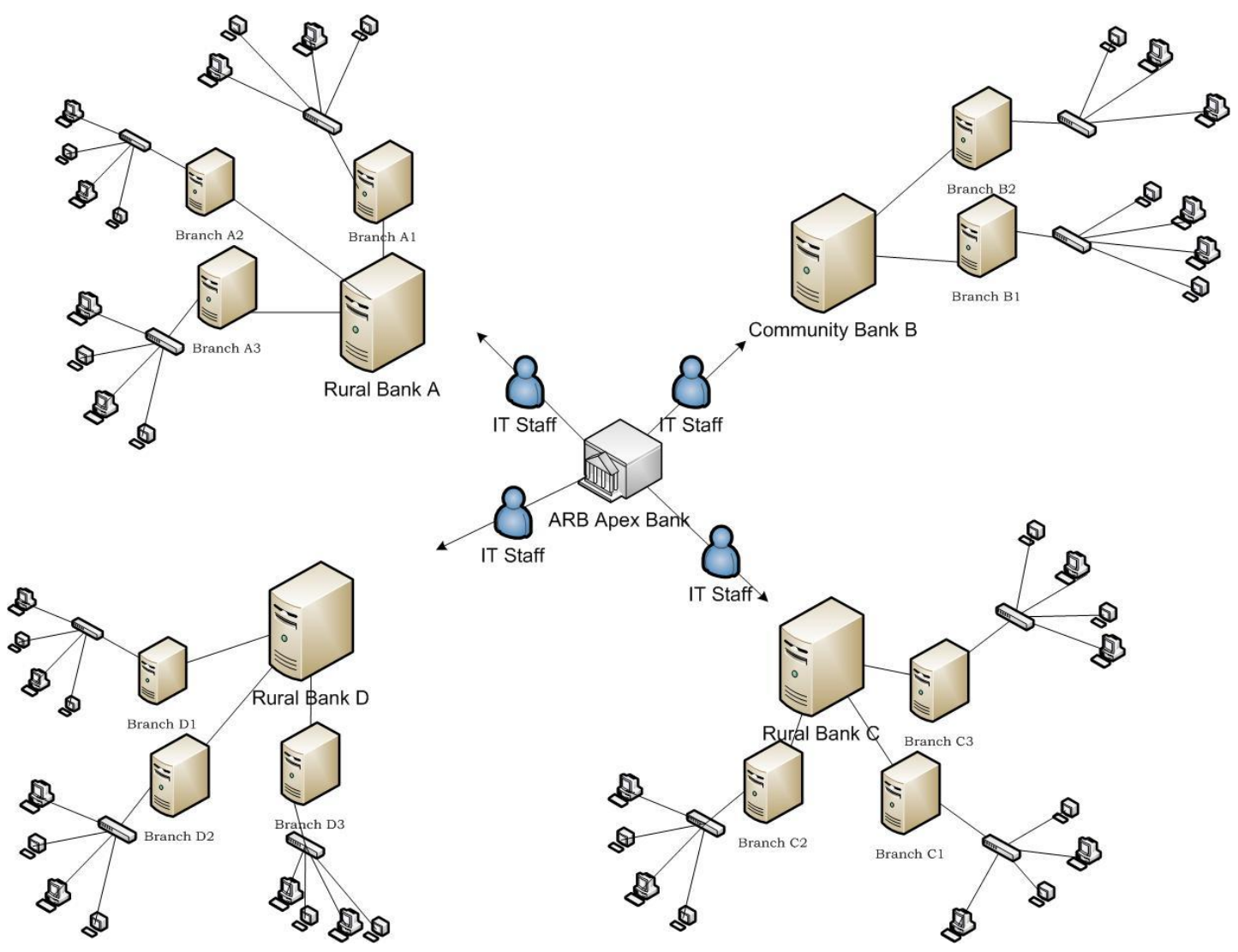

Figure 1. The ICT infrastructure architecture and management under the RFSD

Under the RFSP, IT staff from the supervisory bank (ARB Apex Bank) would visit each rural or community bank to do the computerization on the premises of the bank. The Rural or Community bank will network all its branches to the headquarters as shown in figure 1 above. ARB Apex bank staffs were in charge of all the Installations, Configuration and Training of the RCBs IT staff. Each of the RCBs used its own servers and banking software. The computerization of the RCBs to their various branches made banking or financial services easily available and assessable to rural communities and boosted the rural economy. However, this brought pockets of installations all over the country and managing all the installations by the supervisory bank became tedious and a daunting task.

\section{Millennium development authority (MiDA)}

The Millennium Development Authority (MiDA) in its bid to accelerate the growth of the rural economy, sponsored the rural banks computerization project in 2009. The project intends connect all the over 130 rural and community banks through the provision of Information Communications Technologies (ICT) to improve financial service delivery and support to local enterprises. The USD 25 million project is under the under the Ghana Rural Banks Computerizations and Inter Connectivity Project. The project involved the construction of a central data centre at ARB Apex Bank, the distribution and installation of electric generators, local area network, satellite-based Wide Area Network, personal computers and accessories.

The project was staggered into several phases, with the first phase focusing on infrastructure development. The first phase was the development of the infrastructure of the data centre at the ARB Apex Bank in Accra. This was to serve as the data centre for the private cloud on which all the branches of the rural or community banks would be connected to. The second phase was the deployment of an eMerge Banking Software (Temenos T24 Core Banking Application Software). This involved the deployment of the Temenos T24 Core Banking Application Software on the client computers of the over seven hundred 
(700) rural and community bank branches of the over one hundred and thirty (130) RCBs scattered all over the ten (10) regions of Ghana. Each of the client computers of the RCB branch connected directly through a simple web server located at each branch.

At the inauguration of the first RCB to be connected to the ARB Apex Bank; that is Dangme Rural Bank, the then Deputy Governor of the Bank of Ghana, Mr. Millison Narh, urged the Rural or Community bank's management as well as the IT staff at ARB Apex bank data centre to ensure the security of the system and training of staff to enhance customers' confidence indicating that the expected benefits of the project was to ensure easier access to more varied and cheaper banking services, efficient customer service delivery and making the needs of customers central to the banking business. The Head Internal Control, ARB Apex Bank, Mr. Hyginus Zon tasked the board and management to institute a risk management policy to identify, assess, monitor and control operational and credit risks and reiterated that the bank must also strengthen its internal control mechanisms to ensure that adequate and effective measures were in place to enhance standards and improve performance.

The ICT infrastructure and management under the MiDA sponsored project as such connected all RCBs branches to a centralized data centre, as depicted in figure 2 .

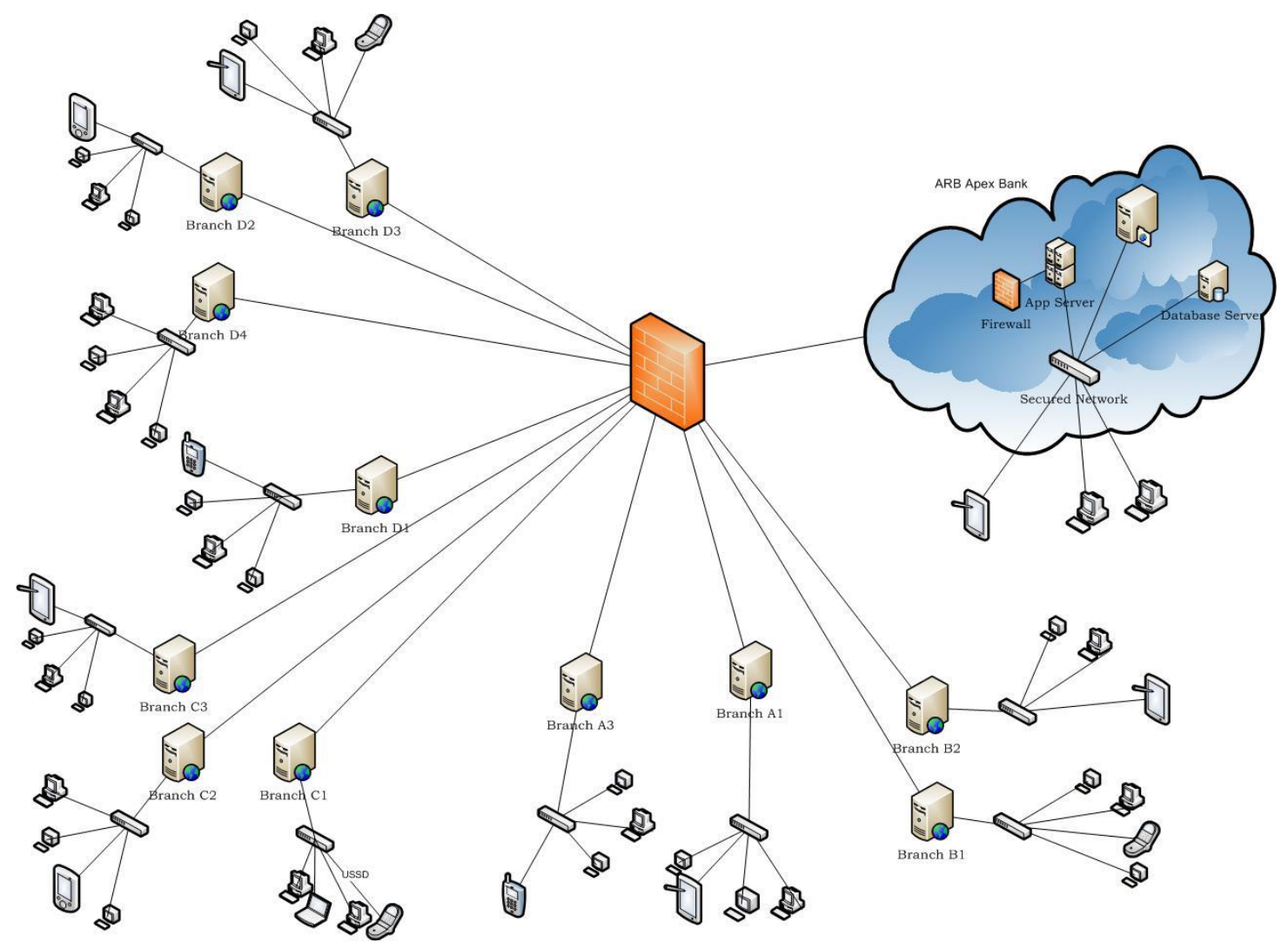

Figure 2. ICT infrastructure network of RCBs to data centre of ARB apex bank.

\section{Benefits of the MiDA project}

The use of the private cloud system under the MiDA project with ARB Apex hosting the data centre has brought lots of benefits to the Rural and Community banks in particular and the Ghana as a whole through its rural development. Some of the benefits include;

- The total cost of ownership (TCO) of the IT infrastructure has drastically reduced. Even though the project was initiated with the first two years being fully funded, the RCBs started paying to the use 
DOI: $10.21522 /$ TIJAR.2014.04.02.Art002

ISSN: $2520-3088$

of the IT infrastructure from 2011, this increase the financial commitment on the RCBs but the overall TCO has reduced.

- ARB Apex bank now has more control over the RCBs infrastructure data and, allowing it to intervene promptly. IT department is able monitor application deployment and use advanced analytics to predict and prevent bottlenecks and downtime. This has made the supervisory bank more efficient in its supervision.

- ARB Apex Bank has been able to rollout several products unto the rural and community banking industry. SMS alert was initially implemented to alert customers of all on bound cash deposit. After successful implementation of the SMS-alert, the Apex Bank introduced the e-Susu. The e-Susu is an App that runs on android, iOS as well as windows operating systems, making it accessible on almost all smart phones. The e-Susu App can also be executed using Unstructured Supplementary Service Data (USSD) code. This makes it possible to operate the e-Susu app on even feature phones. The mobilization agents visits the customers at their locations and receive funds. The agents capture the funds received using the e-Susu app, once the transactions is completed the customer receives an SMS notification.

- This system has increase data security and limited fraud. The use of the data centre has reduced the vulnerability of the RCBs when each of them had their own servers and operated from their headquarters. Other electronic products that has been rolled out by ARB Apex bank such the SMSAlert, e-Susu has almost eliminated fund suppressing by tellers and mobilization agents.

- The ARB Apex Bank is in the final stages of implementing a new e-Product know as u-connect which would make it possible for customers to have access to their funds electronically. Customers would be able to transfer funds from their account to any other rural or community bank account all over the country and also transfer funds from their account to mobile money accounts. The uConnect like the e-Susu runs on all the major smart phone operating systems as well as running on a USSD code.

- Overall, it has made the RCBs very competitive.

\section{Challenges}

The ARB Apex Bank has made lots of strive but there has been some few challenges as outlined by the Deputy ICT manager. One of the major challenges has been financial commitment. The cost of running the system has over the years not changed in dollar terms but the cedi equivalent has appreciated over $400 \%$. Secondly, some of the RCBs have grown bigger and demand more services, however since all the RCBs are connected to the system, it has become almost impossible to roll out services for only some RCBs without the others. Hence there is no technological leverage between the RCBs. Lastly, since most of the commercial banks in the country use the same Core Banking Software as used by the RCBs currently, the turnover rate of the IT staff is very high. This means the Supervisory bank keeps training new IT staffs only for them to move to the commercial banks.

\section{Conclusion}

With the support of Government of Ghana and International development Partners, ARB Apex Bank has served effectively as the supervisory bank for the RCBs and the management of the ICT infrastructure of the RCBs.

ARB Apex Bank has progressively introduced high level technology into Rural and Community banking, revolutionizing the rural and community banking industry and making them very competitive even on the international space. Some of the RCBs have been able to compete favourable with other well-known commercial banks in their operational area. 


\section{References}

[1].Awo, J. P., \& Akotey, J. O. (2012). Financial Performance of Rural Banks in Ghana: A Case Study of Naara Rural Bank.

[2].Business News, November 20, 2010, MiDA- sponsored rural banks computerisation project start operations

[3].Chan, F. M. (2002, October). ICT in Malaysian schools: Policy and strategies. In a Workshop on the Promotion of ICT in Education to Narrow the Digital Divide (pp. 15-22).

[4].Humphreys, E. (2011). Information security management system standards. Datenschutz und DatensicherheitDuD, 35(1), 7-11.

[5].Miller, J., \& Doyle, B. A. (1987). Measuring the effectiveness of computer-based information systems in the financial services sector. MIS quarterly, 107-124.

[6].Project Completion Digests - 2010 - Ghana Rural Financial Services Project (RFSP). Available at https://operations.ifad.org/documents/654016/2154e360-5324-429a-a27c-d2661bb384af (Accessed 14th August, 2017).

[7].Susanto12, H., Almunawar, M. N., \& Tuan, Y. C. (2011). Information security management system standards: A comparative study of the big five. International Journal of Electrical Computer Sciences IJECSIJENS, 11(5), 23-29.

[8].Tshinu, S. M., Botha, G., \& Herselman, M. (2008). An integrated ICT management framework for commercial banking organizations in South Africa. Interdisciplinary Journal of Information, Knowledge \& Management, 3.

[9].Zakaria, M. M. (2013). Evaluation of operational efficiency of the Temenos T24 Core Banking Software on rural banks in Ghana: a case study of South Akim rural Bank Ltd, Eastern Region, Africa Development and Resources Research Institute (ADRRI) Journal, Vol. I, No.1, pp. 40-49. 